\title{
A UTILIZAÇÃO DO WHATSAPP COMO FERRAMENTA MOTIVADORA NO ENSINO DE LÍNGUA PORTUGUESA PARA ALUNOS SURDOS
}

\author{
Fábia Sousa Sena (UFPB) \\ Denilson Pereira Matos (UFPB) \\ Marianne Carvalho Bezerra Cavalcante (UFPB)
}

Resumo: O objetivo deste trabalho é demonstrar como a ferramenta WhatsApp pode ser utilizada como dispositivo pedagógico para o letramento, em Língua Portuguesa, de alunos surdos do Ensino Fundamental nos anos finais, de uma maneira eficiente e prazerosa, estimulando sua produção textual. O WhatsApp é um software que apresenta uma interface atrativa e descomplicada, podendo ser utilizado para troca de mensagens instantâneas de textos, áudios e vídeos. O recurso oferece potencialidade de uso, funcionando como dispositivo pedagógico (LEMOS; MATOS, 2016), inclusive no letramento do surdo, que, no Brasil, está baseado na Lei 10.436/02, que estabelece a LIBRAS como L1 no currículo do surdo e a Língua Portuguesa, como L2, na modalidade escrita. A prática segue a concepção sociocultural do desenvolvimento humano e admite a aprendizagem como processual e socialmente mediada. Como metodologia, adotamos a pesquisa qualitativa de natureza interpretativista e a fundamentação teórica segue postulados de Quadros e Schimiedt (2006), Lacerda (1998), que norteiam seus trabalhos acerca do letramento do surdo, além de estudiosos como Coscarelli (2010), que utilizam estratégias para integrar tecnologias às atividades práticas em sala de aula. A partir de sequência didática, aplicamos oficina que utilizou da ferramenta WhatsApp com os alunos do 7ㅇ ano do Ensino Fundamental, tendo em vista que o recurso visual em questão favorece o processo de letramento do sujeito surdo e os textos multimodais oferecem grandes contribuições, promovendo novos caminhos para a construção de conhecimentos, estabelecendo a construção de práticas sociais de leitura e escrita de forma significativa para os mesmos. Um dos resultados mais relevantes repousa no fato de que o educador é beneficiado em sua prática pedagógica, que se apresenta com maior eficácia e de maneira lúdica. Em relação aos alunos surdos, a metodologia favorece a interação com a atividade e com os demais alunos.

Palavras-chave: Letramento; Aluno Surdo; WhatsApp. 
Abstract: The aim of this work is to demonstrate how the WhatsApp tool can be used as a pedagogical device for the literacy, in Portuguese language, of deaf students in Elementary Years, in an efficient and pleasant way, stimulating their textual production. WhatsApp is a software that presents an attractive and uncomplicated interface and can be used for instant messaging of texts, audios and videos. What can be used as a pedagogical activation mechanism (LEMOS; MATOS, 2016), including the literacy of the deaf, which in Brazil is based on Law 10.436 / 02, which establishes the LIBRAS as L1 in the curriculum of the deaf and the language Portuguese, as $L 2$, in written form. The practice follows sociocultural and socially mediated language. As methodology, we adopted the qualitative research of interpretative nature and the theoretical foundation follows postulates of Quadros and Schimiedt (2006), Lacerda (1998), who guides their works on the literacy of the deaf student, as well as scholars such as Coscarelli (2010), that use strategies to integrate technologies into practical classroom activities. From a didactic sequence, we applied a workshop that used the WhatsApp tool with the students of $7^{\text {th }}$ grade of Elementary School, in view of the fact that the visual resource in question favors the process of literacy of the deaf and the multimodal texts offer great contributions, promoting new ways for the construction of knowledge, establishing the construction for social practices of reading and writing in a meaningful way to them. One of the most relevant results is on the fact that the educator is benefited in his pedagogical practice, wich presents itself more effectively and in a playful way. With regard to deaf students, the methodology favors interaction with the activity and with other students.

Keywords: Literacy; Deaf students; WhatsApp.

\section{INTRODUÇÃO}

O letramento do aluno surdo no âmbito educacional é obstáculo a ser superado e há algum tempo inquieta diversos estudiosos da área, uma vez que as mudanças ocorridas nas últimas décadas, em termos de inclusão, levam a diversos questionamentos acerca da aprendizagem desse estudante na sala de aula e, mais especificamente, nas aulas de Língua Portuguesa. 
De acordo com a Lei 10.436 de 2002, a LIBRAS - Língua Brasileira de Sinais deve ser concebida como língua materna no currículo do aluno surdo e a língua portuguesa como segunda língua, a ser utilizada na modalidade escrita. Desde então, os estabelecimentos educacionais vêm adaptando os seus currículos de modo a atender a demanda linguística da referida clientela, visando que este estudante seja considerado em sua individualidade, reconhecendo a importância de cada uma dessas duas línguas para a formação desse sujeito, corroborando com o processo de letramento de maneira satisfatória.

Ressalta-se que a motivação deste trabalho repousa numa reflexão que tenta colocar o ensino de língua "não apenas como um mecanismo de inclusão, mas como objeto de reflexão linguístico-teórico, fazendo-o por meio de questões teórico-práticas que estão presentes no universo do debate sobre o ensino imerso na cultura surda." (MATOS; SAÚDE, 2012).

Há muito, debate-se sobre a necessidade de incluir os surdos na sociedade, no entanto, esta inclusão nem sempre se concretiza, pois o indivíduo surdo é obrigado a aprender a língua portuguesa para poder acessar o mundo letrado. [e nem sempre a sociedade tem a mesma disponibilidade]. (MATOS; SAÚDE, 2012, p.2) 
Segundo Lacerda (1998, p.38), “a linguagem é uma atividade constitutiva dos sujeitos, pois é por meio dela que os seres humanos se apropriam da cultura a sua volta e têm acesso aos conhecimentos", tendo em vista que agimos mediados por essa linguagem. A língua de sinais representa um papel de grande importância no processo de desenvolvimento da criança surda, pois através dessa língua o surdo interage com o mundo ao seu redor e se constitui enquanto grupo linguístico minoritário, sendo esta língua, condição necessária para a aprendizagem da língua portuguesa, na modalidade escrita.

De acordo com Vygotsky (1991, p.85), a escrita é uma função linguística que difere da fala oral tanto na estrutura como no seu funcionamento, desse modo, podemos compreender que, no processo do letramento do aluno surdo, o som deve ser isentado, uma vez que a sua ausência não impede o domínio da língua escrita.

Tomamos por base a definição de fala oral, como a necessidade do ser humano, enquanto ser que precisa interagir com o mundo à sua volta, através do uso de um dom que the é inato, a saber, a capacidade de expressar-se através da linguagem.

De acordo com Marcuschi (2005, p.17), é possível definir o homem como um ser que fala e não como um ser que 
escreve, porém o autor ressalta que a oralidade não é superior à escrita, tendo em vista que fala e escrita possuem características próprias, embora utilizem o mesmo sistema linguístico.

Com isso, podemos perceber que a proficiência de uma língua além de estar ligada às suas modalidades linguísticas, está relacionada também, aos mecanismos cerebrais que são responsáveis pela internalização das regras gramaticais dessa língua.

Importante ressaltar que o ouvinte poder contar com a audição para aquisição de uma determinada língua, seja na modalidade oral ou escrita, contribui consideravelmente com a sua aprendizagem, o que não ocorre no caso do surdo, que contará especialmente com a língua de sinais, sendo o seu processo de aquisição baseado nas significações contextuais e no domínio das regras gramaticais, tendo em vista que estes não estão relacionados ao ouvir e/ou ao falar.

Porém, apesar da língua de sinais ser a porta de entrada para a língua portuguesa, atuando como língua de significação, de acordo com Karnopp (2005, p.25) nem todo surdo fluente em língua de sinais apresenta um bom desempenho na leitura e escrita da língua portuguesa, que possui modalidade oralauditiva. Essa situação se instaura, principalmente, devido 
à forma como as atividades são expostas em sala de aula, na maioria das vezes, com exercícios artificiais que não apresentam a função social e prazerosa dessa escrita.

Assim, o presente escrito traz uma reflexão acerca de como a produção de texto pode ser incentivada em sala de aula do Ensino Fundamental nos anos finais, desde que se utilize de metodologias diferenciadas, com o apoio de aparatos tecnológicos. Uma vez que o nosso aluno (ouvinte ou não), sendo nativo digital, está em contato permanente com essas tecnologias, o objetivo de integrar as tecnologias ao processo de ensino-aprendizagem, torna o processo mais atrativo e motivador.

Nesse sentido, com vista a fazer um recorte mais adequado ao que aqui decidimos chamar de tecnologias, de fato, estamos tratando de um tipo de Ferramenta Virtual Não Exclusiva à aprendizagem - FVNexA: WhatsApp. Assim:

\begin{abstract}
A apresentação das ferramentas virtuais como possibilidades concretas, facilitadoras e úteis para o desenvolvimento de atividades pedagógicas e linguísticas afirma uma posição não preconceituosa sobre a internet. Posição que demonstra certa cautela e consciência de que podemos fazer boas escolhas, se formos indivíduos críticos e capazes de sermos sujeitos diante da Indústria cultural e não objetos dela. (MATOS; RODRIGUES, 2013, p.3)
\end{abstract}


Ressalte-se, também, que a valorização das ferramentas virtuais não prescinde a ação social do professor, na qualidade de agente que estimula formação de significados, conforme indicado, no Quadro I (Ação Social e Letramento) a seguir, por Matos; Lemos (2015) em um congresso realizado em Cartagena, Colômbia na Univesidad San Buena Ventura:

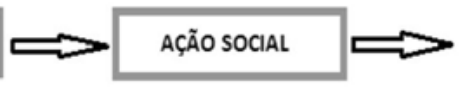

E-COMMERCE

FERRAMENTA VIRTUAL.

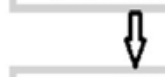

ALUNO

(EJA)

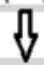

CONSTRUÇÃO DE

SIGNIFICADOS

CULTURA

LETRAMENTO/

LETRAMENTO DIGITAL

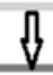

CULTURA

Quadro I: Ação Social e Letramento Digital. Fonte: Memorias Coloquio sobre interdisciplinariedad en la formación del Licenciado en Lenguas Extranjeras - Ciflex 2: Cartagena de Indias: 2015 (MATOS; LEMOS, 2015, p.280)

Portanto, um tipo de ferramenta virtual, conforme o Quadro I, uma plataforma de e-commerce, por exemplo, pode funcionar como dispositivo pedagógico. Logo, o mesmo pode suceder na utilização do WhatsApp: o diferencial repousa na ação social do professor e não exatamente na ferramenta virtual a que se faz uso. 
Assim, vislumbramos demonstrar por meio deste estudo como a ferramenta digital WhatsApp pode ser utilizada enquanto dispositivo pedagógico para o desenvolvimento do letramento em língua portuguesa para alunos surdos do Ensino Fundamental nos anos finais, tendo em vista que - WhatsApp é um software que apresenta uma interface atrativa e descomplicada, podendo ser utilizado para troca de mensagens instantâneas de textos, áudios e vídeos. $\mathrm{O}$ recurso oferece grandes potencialidades de uso pedagógico no letramento do sujeito surdo, usuários da Língua Brasileira de Sinais - LIBRAS.

A pesquisa foi realizada numa escola do município de João Pessoa, que apresenta a proposta bilíngue para surdos, sendo executada através de uma oficina, portanto, trata-se de uma pesquisa de natureza pesquisa-ação, interpretativista, realizada por meio de uma abordagem qualitativa.

O presente escrito segue a perspectiva interacionista de Vygotsky (1991), sendo subsidiado pelos trabalhos de alguns estudiosos acerca da surdez, como: Karnopp (2005), Lacerda (1998), Quadros e Schimiedt (2006), dentre outros que se preocuparam em apresentar para a nossa sociedade uma nova forma de enxergar a educação do surdo, viabilizando estudos voltados para uma discussão ampla acerca do tema, 
além de estudiosos como Rojo (2012); Coscarelli (2010), que norteiam a análise das estratégias utilizadas para integrar as tecnologias às atividades práticas em sala de aula.

\section{AQUISIÇÃO DA LÍNGUA PORTUGUESA NA MODALIDADE ESCRITA POR ALUNOS SURDOS}

A discussão sobre a aprendizagem da língua escrita por sujeitos surdos, apesar de relevante, ainda se encontra em fase inicial no Brasil, uma vez que encontramos poucas pesquisas que abordem tal perspectiva. No entanto, é imprescindível a necessidade da discussão por parte dos educadores que atuam diretamente com o aluno surdo, uma vez que muitos dos alunos surdos concluem o Ensino Fundamental sem a proficiência mínima exigida em língua portuguesa.

De acordo com Quadros e Schmiedt (2006),

Atualmente a aquisição do português escrito por crianças surdas ainda é baseada no ensino do português para crianças ouvintes que adquirem o português falado. A criança surda é colocada em contato com a escrita do português para ser alfabetizada em português seguindo os mesmos passos e materiais utilizados nas escolas com as crianças falantes de português. (2006, p.23)

Nessa acepção, um dos grandes problemas enfrentados atualmente na aquisição da língua portuguesa, na 
modalidade escrita, pelo aluno surdo, além da falta de sensibilidade, é a falta de conhecimento da importância do trabalho diferenciado com materiais concretos e visuais que contribuem não apenas com o letramento do surdo, mas torna dinâmica a aula e aprendizagem dos demais alunos.

Entretanto, na maioria das nossas salas de aulas nos deparamos com exercícios que retratam a língua como um conjunto de regras gramaticais, classificações, um ensino arraigado sob a ótica da metalinguagem, em que o professor se utiliza de uma metodologia extremamente tradicional.

O método tradicional de aprendizagem apresenta os conteúdos de forma mecânica, não relacionando com a realidade do aluno, sendo estes conteúdos apresentados como verdades absolutas, apontando o professor como o transmissor e detentor do saber. Esse método de ensino tradicional leva a formação de alunos decodificadores da língua, alfabetizados, mas não letrados. Na maioria das vezes, esses alunos, realizam a leitura do texto, mas não compreendem o que foi lido, outras vezes, levam anos para a construção da habilidade e competência da leitura, ao invés de conceberem a língua portuguesa como língua viva, praticada em nosso dia a dia, dotada de subjetividade e de cultura. 
Segundo Ribeiro, Santos e Furtado (2015, p.99), se faz necessário ao invés "de pensar a alfabetização como momento de aprender palavras, frases soltas, para a consecutiva estruturação da escrita, precisamos pensá-la como uma prática social importante para a construção do conhecimento". Essa é uma demanda que concebe a escrita como uma modalidade da linguagem em consonância com a funcionalidade social.

Assim, faz-se necessário reforçar a importância do trabalho epilinguístico, atribuindo sentido à produção de textos realizados pelos alunos surdos, com o objetivo de debruçarse sobre o material produzido, como objeto de análise e reflexão, levando em consideração as especificidades e divergências da língua portuguesa e da língua de sinais, além de verificar os traços da ortografia dessa língua materna, quando os alunos produzem textos escritos na língua portuguesa.

Essa nos parece uma excelente oportunidade para refletirmos acerca da importância de se compreender que estamos nos referindo a duas línguas distintas, legítimas, com regras gramaticais próprias e usos sociais diversificados, tendo a sensibilidade para percebermos que a apropriação da língua portuguesa, na modalidade escrita, pelo aluno surdo, é um direito a ser garantido. Para tanto, esse direito 
só será efetivamente garantido se houver a sensibilidade do educador em perceber a necessidade de avaliar a sua própria prática, buscando diferentes modos de trabalhar os conteúdos a serem abordados em sala de aula.

De acordo com Costa e Cavalcante (2015, p.77), para a aprendizagem da língua portuguesa por sujeitos surdos, "as estratégias de letramento em português escrito não poderão tomar como referência a consciência fonológica, visto que a língua de sinais é visuoespacial, assim, as pistas não serão fonológicas, mas visuais". Uma vez que o aluno surdo compreende o mundo através da visão, faz-se necessário que o professor, seguindo esse pensamento, defina os procedimentos a serem aplicados, levando em consideração a condição do surdo, apropriando-se de estratégias que valorizem a condição linguística desse aluno, sendo o recurso tecnológico de grande contribuição, uma vez que a tecnologia faz parte do nosso dia a dia e não podemos mais tratá-la como algo dissociado da sala de aula, já que é visualmente acessível ao aluno surdo.

\section{A FERRAMENTA VIRTUAL WHATSAPP COMO DISPOSITIVO PEDAGÓGICO}

Com a introdução das tecnologias digitais e, consequentemente, da internet no meio educacional, notoriamente foi percebida uma expansão de possibilidades 
de comunicação do aluno surdo com os alunos ouvintes, visto que essa nova forma de comunicação favorece não apenas a sua interação com os ouvintes, mas contribui também com a sua aprendizagem, em virtude da apropriação do visual por parte do aluno surdo para sentir/perceber o mundo à sua volta. Conforme Stumpf (2010),

do ponto de vista dos surdos o uso do computador e da Internet inaugurou uma nova dimensão às suas possibilidades de comunicação, pois são tecnologias acessíveis visualmente. Se, para os ouvintes, elas abriram perspectivas que levaram a modificações profundas nos usos e costumes de toda a sociedade, para os surdos, essas mudanças podem ser ainda mais significativas. $(2010$, p.2)

As tecnologias digitais vêm impactando as relações sociais, assim como, os modos de produção de conhecimento, por meio das práticas de conhecimento e das práticas de letramento e escrita. De acordo com Dias (2012, p.99), essas novas práticas de leitura e escrita requerem da escola trabalhos focados nessa nova realidade. Essas ferramentas virtuais, utilizadas corretamente, facilitam a inclusão do aluno surdo, contribuindo com sua aprendizagem.

Assim, a escola, ao utilizar as ferramentas virtuais em sala de aula, proporciona não somente a inclusão dos alunos 
surdos, mas assegura uma aprendizagem dinâmica e eficaz em todos os âmbitos, principalmente, no que diz respeito ao seu letramento em língua portuguesa.

Como os alunos surdos se apropriam do mundo ao seu redor através de experiências visuais, os recursos tecnológicos oferecem grandes contribuições, uma vez que favorece as práticas dos seus mediadores, promovendo novos caminhos para a construção de conhecimentos.

Além das tecnologias digitais possuírem uma grande aceitação pela comunidade surda, a utilização desses recursos, em sala de aula, motiva todos os alunos deficientes ou não, proporcionando uma aprendizagem lúdica.

De acordo com Coscarelli (2010):

A escola não deve perder essa oportunidade de incorporar as novas tecnologias, sobretudo as digitais, em suas práticas educativas. Acredito que, neste momento, ela precisa de projetos e pesquisa que possam Ihe oferecer apoio, auxiliando, assim, a reflexão sobre a melhor forma de usar essas tecnologias como recurso didático e sobre como a escola pode ajudar seus alunos a desenvolver competências e habilidades importantes para o letramento digital. (2010, p.524)

Contudo, a escola, cada vez mais, tem como papel preponderante apropriar-se das tecnologias digitais como 
ferramenta para auxiliar na sedimentação dos conteúdos, visando à participação dos alunos surdos nas aulas.

O principal objetivo da utilização dessas tecnologias em sala de aula é de alcançar uma melhor aprendizagem, tendo em vista que a utilização destas favorece o trabalho desenvolvido pelos professores, facilitando a interação dos educandos, por serem tecnologias visualmente acessíveis, que contribuem no processo de ensino-aprendizagem.

Desse modo, percebemos que o smartphone é utilizado por todos os nossos alunos, sendo um instrumento que agrega diversas funções, podendo ser utilizado para contribuir com o educador em busca da socialização do conhecimento. Assim, decidimos utilizar a ferramenta WhatsApp para trabalhar a construção de textos em língua portuguesa, com a finalidade de contribuir para o letramento do aluno surdo.

O WhatsApp é um aplicativo para smartphones que apresenta uma interface atrativa e descomplicada, podendo ser utilizado para troca de mensagens instantâneas de textos, fotos, áudios e vídeos por meio da internet. O recurso oferece grandes potencialidades de uso pedagógico no letramento do sujeito surdo, usuários da Língua Brasileira de Sinais - LIBRAS. Para tanto, nos utilizamos de uma oficina em sala de aula do Ensino Fundamental nos anos finais, através 
da construção de uma sequência didática para colocar em prática a metodologia planejada, que segue descrita a seguir.

\section{PROCEDIMENTOS METODOLÓGICOS E ANÁLISE DOS DADOS}

A presente pesquisa foi conduzida com base nos pressupostos teórico-metodológicos da pesquisa qualitativa, realizada por meio de um estudo pesquisa-ação. Foi desenvolvida no município de João Pessoa, tomando como base uma escola de tempo integral que apresenta a proposta de bilinguismo. A escola em questão nos serviu de amostra para a construção do resultado final.

O município de João Pessoa conta com 98 (noventa e oito) escolas de Ensino Fundamental, sendo que 16 (dezesseis) destas escolas funcionam em regime de tempo integral e 85 (oitenta e cinco) Centros de Referência de Educação Infantil (CREIS), distribuídos em 9 (nove) polos.

Atualmente, o referido município atende o total de 176 (cento e setenta e seis) alunos surdos distribuídos em 27 (vinte e sete) escolas e 2 (dois) CREIS. $O$ atendimento a esses alunos é realizado nas escolas regulares de Educação Infantil e Fundamental, preconizando um atendimento de qualidade, desenvolvendo a política de inclusão e a proposta bilíngue, conforme a legislação em vigor no país. 
Os alunos são atendidos nas escolas bilíngues com a presença do instrutor, intérpretes e professor de Libras. No entanto, apesar da existência de muitas propostas educacionais, ainda são muitos os entraves na formação desses alunos, uma vez que o modo como o professor aborda os conteúdos e atividades, muitas vezes, não são acessíveis à criança surda, que necessita da presença do intérprete para traduzir e adequar as informações, com o intuito de viabilizar o melhor aproveitamento das disciplinas.

Como instrumento para o alcance dos objetivos, utilizamos a técnica de coleta de dados por meio da realização de oficina em sala de aula, utilizando a ferramenta WhatsApp, através do smartphone. A escola serviu como campo de trabalho para desenvolvimento da pesquisa e locus para coleta dos dados, além de ser um local de diálogo com os gestores escolares, professores e intérpretes sobre a maneira como tratam as questões relacionadas ao letramento do aluno surdo em língua portuguesa.

A intervenção da pesquisa se realizou mediante a aplicação de uma oficina de produção textual, por meio de uma sequência didática baseada na perspectiva de Dolz, Noverraz e Schneuwly (2004), que apresentam uma preocupação em nos fornecer elementos que contribuam para o ensino da língua. Os autores nos expõem uma metodologia de ensino 
por meio de "sequência didática" para o trabalho com os gêneros textuais na sala de aula do ensino fundamental. Sua apresentação ocorre de maneira modular nos possibilitando uma aprendizagem mais sólida, à medida que essa sequência nos oferece uma forma consistente para o desenvolvimento das estratégias a serem utilizadas em sala de aula pelos educadores e educandos.

Ainda de acordo com Dolz, Noverraz e Schneuwly (2004, p.53), "os objetivos de uma sequência didática, devem adaptar-se às capacidades e às dificuldades dos alunos nela envolvidos", visando à promoção da aprendizagem dos referidos alunos.

Desse modo, aplicamos uma oficina que se utilizou da ferramenta WhatsApp com os alunos do 70 ano do Ensino Fundamental, tendo em vista que o recurso visual em questão favorece o processo de letramento do sujeito surdo e os textos multimodais oferecem grandes contribuições, promovendo novos caminhos para a construção de conhecimentos, estabelecendo a construção de práticas sociais de leitura e escrita de forma significativa para os sujeitos citados.

A aplicação dessa oficina com os alunos do 7ํano do Ensino Fundamental teve a finalidade de demonstrar a maneira que a ferramenta WhatsApp pode ser utilizada como dispositivo 
pedagógico para o desenvolvimento do letramento em língua portuguesa para alunos surdos do Ensino Fundamental nos anos finais. Apresentando-a de forma eficiente e prazerosa, estimulando a produção textual e, ao mesmo tempo, o letramento digital. Além de verificar a produção da escrita e compreensão da língua portuguesa, como segunda língua no currículo do aluno surdo, vislumbrando o entendimento e ao mesmo tempo a aceitação da escrita do surdo, que, tendo a LIBRAS como referência, acaba produzindo textos sem alguns registros previstos na gramática da língua portuguesa.

Para tanto, nos apropriamos dos estudos do letramento que refletem no processo de ensino - aprendizagem e destacam níveis de conhecimentos dos educandos surdos e suas práticas sociais de leitura e escrita engajadas numa perspectiva sociointerativista.

Tomamos por base o conceito de letramento estabelecido por Soares (2002, p.145) ao afirmar que "letramento é o estado ou condição de quem exerce as práticas sociais de leitura e escrita, de quem participa de eventos em que a escrita é parte integrante entre as pessoas e do processo de interpretação dessa interação", segundo a autora, o letramento vai além da decodificação das palavras e está relacionado à atuação do indivíduo diante das diversas 
situações do cotidiano, que necessita desse letramento.

$O$ referido letramento se realiza em diferentes espaços da sociedade, mas segundo Kleiman (1995, p.20) "podese afirmar que a escola é a mais importante das agências de letramentos", pois é nela que, de forma planejada e sistemática, o aluno é direcionado a fazer uso das práticas desse letramento.

A Base Nacional Comum Curricular - BNCC orienta as práticas de leitura, abordando a necessidade de “(proporcionar) experiências que contribuam para o desenvolvimento do letramento (ou dos letramentos), entendido como condição de participar de uma diversidade de práticas sociais permeadas pela escrita" (BRASIL, 2017, p.505), apresentando como dimensões:

- o desenvolvimento de habilidades e atitudes envolvidas nos vários tipos de letramentos;

- a reflexão e o reconhecimento dos usos sociais e das condições discursivas envolvidas na produção de texto e sua circulação;

- apropriação dos usos sociais da escrita;

- reflexão sobre os aspectos relativos à forma com os textos se apresentam. (BRASIL, 2017, p.190) 
Levamos em consideração o conhecimento prévio e experiências que os alunos trazem para sala de aula acerca do amplo universo relacionado ao mundo tecnológico, buscando integrar esse conhecimento aos conteúdos escolares, considerando, no processo de aprendizagem, o modo de pensar desses alunos.

Inicialmente, foi realizada a identificação do problema Apresentação da situação - Dificuldade de produção textual dos alunos surdos do 70 ano no Ensino Fundamental. As atividades de produção de texto foram planejadas com a professora de língua portuguesa da turma e participaram da atividade 16 alunos ouvintes e 06 (seis) alunos surdos do 7으 ano do Ensino Fundamental.

Como segundo passo, foi criado um grupo de WhatsApp com os alunos da turma (surdos e ouvintes), professora e a pesquisadora. Após discussão, ficou decidido coletivamente que o tema a ser desenvolvido seria "Preconceito Linguístico".

Assim, como terceiro passo, a professora em sala de aula fomentou a discussão do tema escolhido, numa roda de conversa, apresentando imagens das cinco regiões do Brasil, com a finalidade de introduzir o tema.

Na sequência, como quarto passo, enviamos para o grupo de WhatsApp, os links de três vídeos para que os 
alunos assistissem e realizassem a discussão no ambiente virtual. Os vídeos escolhidos para contemplar o tema, foram: Desvendando as diferentes formas de fala ${ }^{1} r$; Sotaques $e$ expressões do Brasil e As cinco regiões do Brasil ${ }^{3}$.

Nesse momento, a professora e a pesquisadora tiveram o papel de mediadoras da discussão, buscando incentivar todos os alunos a participarem da atividade proposta.

Um dos combinados para a realização da discussão seria o respeito à opinião dos colegas, respeito à ortografia do aluno surdo e a utilização apenas da modalidade escrita, assim, não seriam permitidos a gravação de áudios ou vídeos. O objetivo desse momento também foi trabalhar os eixos da língua portuguesa, voltados para a compreensão leitora e escrita.

No quinto passo, como atividade complementar, foi enviado para o grupo do WhatsApp, um texto em quadrinho, com o objetivo de estimular a discussão sobre o tema citado, ainda com o objetivo de favorecer a utilização da ferramenta digital mais utilizada atualmente no dia a dia dos nossos educandos e incentivar a produção escrita, com o intuito de minimizar o problema identificado acerca da produção escrita dos alunos da turma do 7음 ano.

\footnotetext{
1 https://www.youtube.com/watch?v=HwHfkuRCflc

2 https://www.youtube.com/watch?v=SAiXRi6Rcsg

3 https://www.youtube.com/watch?v=u288EmAWT3g
} 


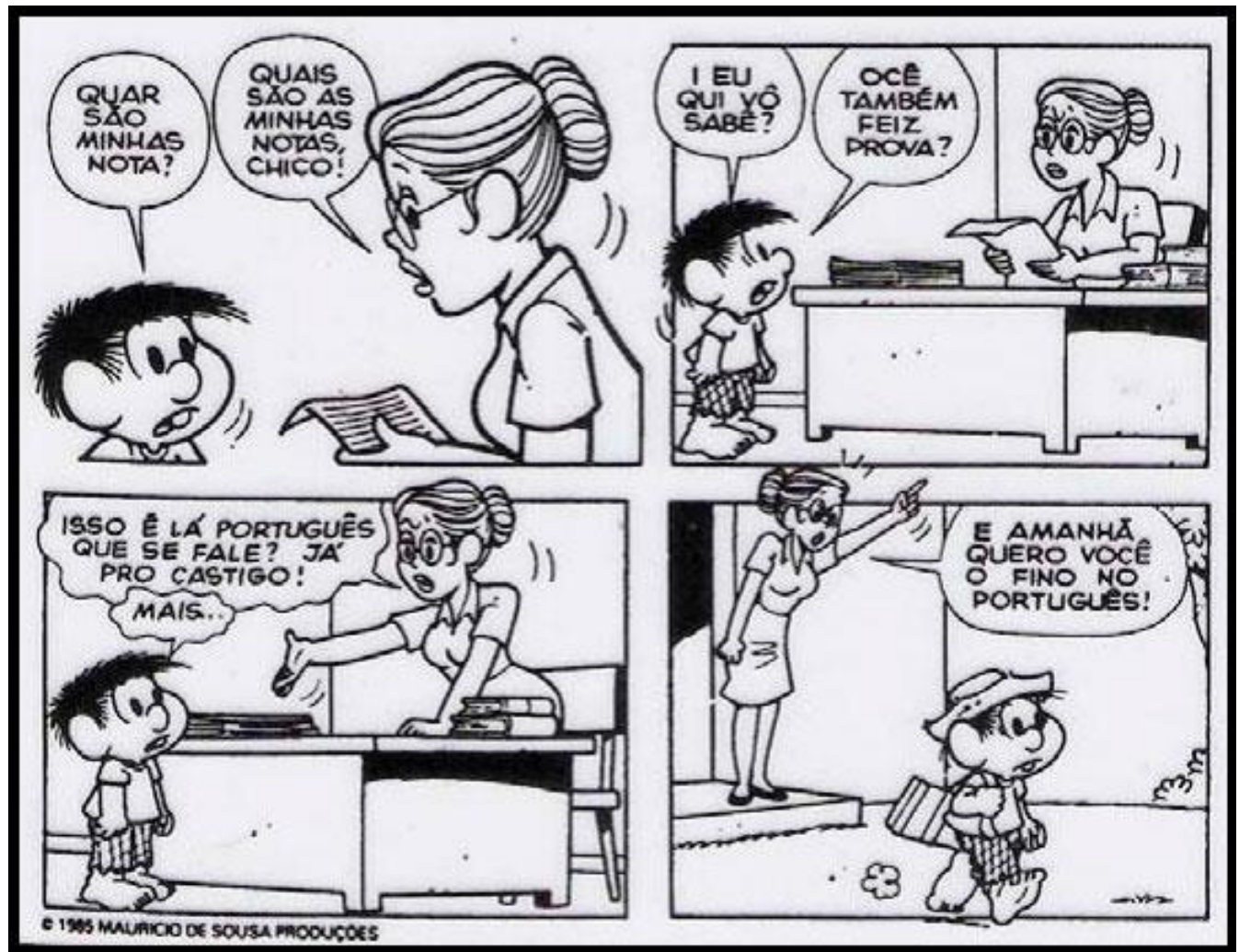

Figura 1. Fonte: http://preconceitos-linguisticos.blogspot.com/2012/04/chico-bento.html Acesso em 05.Nov.2018

Foram estabelecidas para os estudantes as seguintes questões norteadoras: 1. Discuta a relação entre os vídeos assistidos em sala de aula e o texto; 2. Com relação ao posicionamento da professora, no seu ponto de vista, você acha que ela agiu corretamente? Sim ou não? Comente; 3. Caso você estivesse na posição da professora, o seu posicionamento seria o mesmo que o dela ou não? 
E na posição desse aluno, como você se sentiria?; 4. Você já vivenciou uma situação semelhante?

No sexto e último passo, foi realizado o fechamento da discussão que ocorreu em sala de aula com a presença dos alunos, da professora e da pesquisadora.

Essa etapa teve início com a apresentação de um vídeo contendo o depoimento de um surdo sobre a contribuição do WhatsApp como ferramenta facilitadora para a sua produção textual em língua portuguesa e, na sequência, foi realizada a discussão acerca dos textos produzidos pelos alunos no ambiente do WhatsApp. Nesse momento, todos os alunos tiveram a oportunidade de posicionamento acerca do tema abordado, novamente, além disso, também se mostraram suscetíveis à aceitação da diferença linguística do surdo, pois puderam perceber de perto a dificuldade existente desse surdo em relação à aprendizagem da língua portuguesa e como a ferramenta utilizada contribui para esse processo.

Através da referida oficina, foi possível constatar que, nos momentos de leitura e escrita, os alunos surdos demonstraram um grande interesse para a aquisição da $L 2$, pois perceberam importância da língua portuguesa para o seu dia a dia. Desse modo, nas atividades de produção textual que foram analisadas, os alunos conseguem repassar 
a mensagem compreendida, alcançando, assim, os objetivos propostos à oficina. No entanto, nessas atividades ficam comprovadas suas dificuldades em lidar com a produção escrita na língua portuguesa.

Portanto, nossas observações apontam para a importância de se trabalhar a escrita do aluno surdo, em língua portuguesa, na modalidade escrita, por meio de atividades que envolvam práticas diversas com a utilização dos gêneros textuais, desfrutando da multimodalidade como ferramenta necessária para a construção do letramento desse sujeito e dos recursos digitais, estimulando a produção textual, pois como dito anteriormente, se a tecnologia vem impactando no modo da produção da leitura e escrita, a escola precisa fazer uso dessa tecnologia, como forma de abordar os diversos letramentos trazidos por essa era digital.

Em depoimentos, os alunos, tanto surdos como os ouvintes, relataram a importância da utilização de recursos que eles acessam diariamente em sala de aula e o quanto essa atividade foi relevante e prazerosa.

\section{CONSIDERAÇÕES FINAIS}

Através da aplicação da oficina em questão, foi possível perceber que a utilização da ferramenta digital WhatsApp contribui para o processo de aprendizagem da língua 
portuguesa, na modalidade escrita, do aluno surdo, uma vez que estes a utilizam diariamente para comunicação com os seus colegas ouvintes e surdos.

Portanto, demonstraram interesse em realizar as atividades propostas, levando-nos a refletir acerca das discussões sobre as práticas voltadas para esse aluno em sala de aula, as metodologias aplicadas pelos educadores e a formação dos profissionais que atuam diretamente com estes alunos.

A utilização das tecnologias digitais em sala de aula apresenta fundamental relevância tanto para o professor como para os alunos surdos. O educador é beneficiado em sua prática pedagógica, que se apresenta com maior eficácia e de maneira lúdica. Em relação aos alunos surdos, a metodologia favorece a interação com a atividade e com os demais alunos.

Foi observado que, ao utilizar a ferramenta WhatsApp para a realização de atividades de língua portuguesa, os alunos surdos ganharam autonomia, desenvolveram suas atividades com criatividade, além de proporcionar um ambiente motivacional. Percebemos ainda, uma expansão de possibilidades de comunicação do aluno surdo com a comunidade ouvinte, facilitando a sua interação com os 
colegas ouvintes, bem como a sua aprendizagem, tendo em vista que o surdo se utiliza do visual para sentir o mundo à sua volta.

Dessa forma, o uso das ferramentas virtuais em sala de aula auxilia na internalização dos conteúdos, contribuindo satisfatoriamente com $\mathrm{o}$ seu processo de ensinoaprendizagem. Percebemos ainda que tanto a professora como todos os alunos envolvidos na atividade proposta participaram ativamente, sendo estes alunos construtores da sua própria aprendizagem. No entanto, ainda há uma necessidade de repensar as discussões sobre a prática das políticas educacionais voltadas para o aluno surdo e a formação dos profissionais que atuam diretamente com estes alunos.

\section{REFERÊNCIAS}

BRASIL. Ministério da Educação (2002). Secretaria de Educação Especial. Lei no 10.436, de 24 de abril de 2002. Dispõe sobre a Língua Brasileia de Sinais - LIBRAS e dá outras providências. Disponível em https://presrepublica. jusbrasil.com.br/legislacao/99492/lei-de-libras-lei-10436-02. Acesso em 29.Mar.2019.

BRASIL, Ministério da Educação (2017). Base Nacional Comum Curricular. In http://basenacionalcomum.mec.gov.br/. Acesso em 04.Abr.2019.

COSCARELLI, Carla Viana (2010). "A cultura escrita na sala de aula (em tempos digitais)". In: MARINHO, Marildes; CARVALHO, Gilcinei Teodoro (Orgs.). Cultura escrita e letramento. Belo Horizonte: Editora UFMG, p.513-526. 
COSTA, Carlos Rubens de Souza; CAVALCANTE, Marianne Carvalho Bezerra (2015). Diversidade Linguística no Ciclo de Alfabetização. In: BRASIL. Ministério da Educação, Secretaria de Educação Básica. Pacto Nacional pela Alfabetização na Idade Certa. Currículo na perspectiva da inclusão e da diversidade: as Diretrizes Curriculares Nacionais da Educação Básica e o ciclo de alfabetização. Caderno 1. Brasília: MEC, SEB.

DIAS, Anair Valênia Martins (2012). "Hipercontos multissemióticos: para a promoção dos multiletramentos". In: ROJO, Roxane; MOURA, Eduardo (Orgs.). Multiletramentos na escola. São Paulo: Parábola Editorial, p.95-122. DOLZ, Joaquim; NOVERRAZ, Michèle; SCHNEUWLY, Bernard (2004). "Seqüências didáticas para o oral e a escrita: apresentação de um procedimento". In: DOLZ, Joaquim; SCHNEUWLY, Bernard e colaboradores. Gêneros orais e escritos na escola. Roxane Rojo e Glaís Sales Cordeiro (Trads.). Campinas, SP: Mercado das Letras, p.95-129..

KARNOPP, Lodenir Becker (2005). "Práticas de leitura e escrita em escolas de surdos". In: FERNANDES, Eulalia. (Org.) Surdez e Bilinguismo. Porto Alegre: Editora Mediação, p.65-79.

KLEIMAN, Angela (1995). Os significados do letramento: uma nova perspectiva sobre a prática social da escrita. Campinas: Mercado das Letras.

LACERDA, Cristina Broglia Feitosa de (1998). "Um pouco da história das diferentes abordagens na educação dos surdos". Caderno CEDES, 19(46), 68-80, Campinas.

LEMOS, Cléber; MATOS, Denilson Pereira de (2015). "As ferramentas virtuais enquanto instrumentos de ensino: a cultura e a ação social do professor". In: Memorias Coloquio sobre interdisciplinariedad en la formación del Licenciado en Lenguas Extranjeras (Ciflex). Myriam Cabrales Vargas (Comp.). Cartagena de Indias, Colombia: Universidad de San Buenaventura. p.273-291.

LEMOS, C. A. \& MATOS, Denilson Pereira de (2016). Refletindo sobre EaD e Letramento Digital: O que cultura tem a ver com isso?. Curitiba: Editora Protexto. 
MATOS, Denilson Pereira de; SAÚDE, Conceição de Maria Costa (2012). "Refletindo sobre a Libras a partir de conteúdo de aulas de teorias linguísticas em curso de graduação de Letras/Libras". Revista Virtual de Estudos da Linguagem - ReVEL, 10(19), 295-308.

MATOS, Debilson Pereira de; RODRIGUES, Enildo da Paixão (2013). "Ferramentas virtuais na construção de estratégias de ensino: considerações sobre o conceito adorniano de indústria cultural". Interdisciplinar - Edição Especial ABRALIN/SE. 17, Jan./Jun., 517-532, Itabaiana, SE.

MARCUSCHI, Luiz Antônio (2005). Da fala para a escrita: atividades de retextualização. 6.ed. São Paulo: Cortez.

QUADROS, Ronice Müller de; SCHMIEDT, Magali L. P. (2006). Idéias para ensinar português para alunos surdos. Brasília: MEC, SEESP.

RIBEIRO, Tiago. SANTOS, Edivânia S. Machado dos; FURTADO, Luciana Andréia R (2015). "Reflexões sobre leitura e escrita na educação bilingue dos surdos". In: RIBEIRO, Tiago; SILVA, Aline Gomes da (Orgs.). Leitura e escrita na educação de surdos. Rio de Janeiro: Wak Editora.

SOARES, Magda (2002). "Novas práticas de leitura e escrita: letramento na cibercultura". Educação \& Sociedade - Revista da Ciência da Educação, 23(81), Dez., 143-160, Campinas. In http://www.cedes.unicamp.br Acesso em 01.Abr.2019.

STUMPF, Marianne Rossi (2010). Educação de Surdos e Novas Tecnologias. Texto Base - Eixo de formação pedagógica, Cursos de Licenciatura e Bacharelado em Letras-Libras a Distância. Florianópolis, UFSC.

VYGOTSKY, Lev Semyonovich (1991). A Formação social da mente. São Paulo: Martins Fontes.

Fábia Sousa Sena é Doutoranda em Linguística pelo Programa de Pósgraduação em Linguistica da Universidade Federal da Paraíba (PROLING/ UFPB), Mestre em Linguística e Ensino pela UFPB em 2017. Especializada em Supervisão Educacional - FIP em 2005. Graduada em Pedagogia pela Universidade Federal da Paraíba em 2004 e graduanda em Letras Português pelo Instituto Federal da Paraíba (IFPB). Trabalha na Prefeitura 
Municipal de João Pessoa, atuando como Gestora e Supervisora escolar, atuou como tutora EaD no Curso de Especialização em Ciências da Linguagem com Ênfase no Ensino de Língua Portuguesa da UFPB, membro técnico integrante do grupo de pesquisa Núcleo de Estudos Linguísticos Interacionais (NELIN) da UFPB e bolsista do Programa SOMA, coordenado pelo Núcleo de Estudos de Alfabetização em Linguagem e Matemática (NEALIM) da UFPB. Tem experiência na área de Educação, com ênfase em Educação Básica e Supervisão Escolar.

Denilson Pereira Matos é Doutor em Estudos Linguísticos pela Universidade Federal Fluminense (UFF) em 2008; Mestre em Estudos da Linguagem (Língua Portuguesa e Linguística) pela Pontifícia Universidade Católica do Rio de Janeiro (PUC-RJ) em 2003; especialista em Língua Portuguesa pela Universidade do Estado do Rio de Janeiro (UERJ) e em EaD pelo SENAC em 2010. Graduação em Letras, bacharelado e licenciatura com ênfase em Literaturas pela UERJ (1995 e 1997). Atualmente é professor associado na UFPB, coordenador de projeto de graduação do Programa de Licenciatura (PROLICEN) da UFPB, pesquisador UAB/Letras e Libras pela UFPB Virtual e docente do PROLING e do Programa de Mestrado Profissional em Linguística e Ensino (MPLE). Coordenador do curso Lato Sensu CLELP/UFPB/UAB/CAPES.

Marianne Carvalho Bezerra Cavalcante possui graduação em Comunicação Social pela Universidade Federal de Pernambuco (UFPE) em 1989, mestrado em Linguística pela UFPE em 1994 e Doutorado em Linguística pela Universidade Estadual de Campinas em 1999. Atualmente é professora associada da UFPB. Tem experiência na área de Linguística, com ênfase em Aquisição da Linguagem, atuando principalmente nos seguintes temas: aquisição da linguagem, interação mãe-bebê, prosódia, multimodalidade, letramento. É bolsista de produtividade em pesquisa pelo CNPq. 